\title{
Discussion Reform of Education on Course of Discrete Mathematics
}

\author{
Yan Zhang \\ School of Information Science and Technology \\ Jiujiang University \\ Jiujiang, China \\ e-mail: zy_xx_jju@163.com
}

\author{
Hui Zhang \\ School of Information Science and Technology \\ Jiujiang University \\ Jiujiang, China \\ e-mail: taibai2000@163.com
}

\begin{abstract}
This paper confirms the importance of discrete mathematics, determining the teaching contents of the application of computer specialty. According to the teaching experience, this paper analyzes the problems existing in the discrete mathematics course and puts forward the method of teaching reform. These methods include: Improving teaching methods, setting up a teaching website, linking theory with practice, etc. These methods have played a certain role. The teaching effect of discrete mathematics is improved obviously.
\end{abstract}

Keywords-Discrete Mathematics; Reform in Education; Teaching Methods; Teaching Means

\section{INTRODUCTION}

Discrete mathematics courses have been one of the core curriculums for the computer professional since the 70 s of the previous century, and all colleges and universities operating computer professional open the discrete mathematics. But in recent years, discrete mathematics as one of the computer professional courses has been questioned. Universities are reducing intensity of the discrete mathematics courses, and for some colleges operating computer applications the discrete mathematics has been set as an elective course. Such an important course does not draw proper attention. What caused such situation? There are some external factors contributed to this situation such as employment pressure, yet internal course design largely contribute to this situation. This paper analyzes these internal factors, proposes some actions for modifying the curriculums, and aims to reverse the awkward position of discrete mathematics courses.

\section{ANALYSIS ON INTERNAL FACTORS}

\section{A. Unclear set of the courses}

The positioning of the discrete mathematics courses is unclear, which is the key reason why the discrete mathematics is not put at an important position. Many colleges and universities pay heavy attention to developing practicing abilities and employment opportunities. So the course first should be put at a clear position to reflect its significance. Discrete Mathematics course, as a core basic course for the computer professional and a pillar to support the curriculum system of the computer professional, is the fundamental basis of the professional courses for computer professionals. Analysis is as below.
First, the discrete mathematics is an important professional basic course. The analysis and design of data structures and algorithms contains a large number of discrete structure. With the increasing maturity of computer science and technology, more and more thorough analysis technology is applied in practice, in order to better understand future computer science and technology, and students need to have in-depth understanding toward the discrete structure." $"[1]$

Secondly, the discrete mathematics can develop professional abilities of the students and helps the students master the correct professional methodology. Using mathematical language, discrete mathematics describes the state of discrete systems, relations and changes. In the process of learning through this course, students can not only grasp the relationship and the results of the discrete, but also practice their logical reasoning, abstract thinking, symbolic calculus and other capacities.

Finally, the discrete mathematics facilitates capacity development of the students. As innovative resource persons of computer science and technology research, engineering and applications, the students should be able to acquire and apply knowledge, and to innovate. Discrete mathematics teaching plays a very important role in developing students' abilities of acquiring and applying knowledge, and innovative thinking.

\section{B. Classroom teaching is not good enough}

The result of classroom teaching is not good enough according to classroom teaching experiences. Students always don't know where they should start learning the massy discrete mathematics. The discrete mathematics handles discrete variables, and the ways of thinking and solution to problems are different from general mathematics courses as it is hard to change thinking approach of the students. In addition, the current classroom teaching usually depends on "pure mathematics" teaching methods and fails to reveal curriculum dissimilarities between discrete mathematics and general mathematics. It does not reflect roles and importance of such courses, and hence students lack proper interest to learn.

\section{TEACHING CONTENTS OF COURSES OF DISCRETE MATHEMATICS}

The textbooks of discrete mathematics vary from each other, but generally include following contents: mathematical logic, set theory, algebra system, and graph 
theory. Mathematical logic studies mathematical reasoning rules. Set theory is the basis for both mathematics and discrete mathematics. Algebraic system is to study the calculating rules of math. Graph theory studies abstract mathematical structure rules, and it can be applied to study the structural issues related to computer with good results. So these four parts are basis of discrete mathematics.

Computer applications (professional IT direction) talents are primarily engaged in work related to computer applications, and they only require a minimum level of discrete mathematics courses. They just need to simply know form description, transforming, reasoning and proving, to master description and analysis methods of discrete system, and most importantly to be familiar with common actual discrete system model. ${ }^{[2]}$ The course length is generally 52 to 72 sessions. Because of limited length of the courses, the above mentioned four parts of discrete mathematics cannot be covered in details. Therefore the teaching contents should be specified to reflect detailed features of different courses for various professions with different focus, underlining the overall principle of "being enough". The knowledge points, which are not easy to for students to understand and bring least impact on the subsequent courses, can be taught just a little bit or else skipped during classroom hours. These knowledge can be accessible at the teaching web site, and any students who wish to learn can study in this way. The class courses designed based on such new plan are shown in Table $1 .^{[3]}$

TABLE I. DISTRIBUTION OF TEACHING CONTENTS AND CLASSROOM HOURS

\begin{tabular}{|c|c|c|}
\hline Chapters & Contents & $\begin{array}{c}\text { Length of } \\
\text { sessions }\end{array}$ \\
\hline Chapter 1 & Set theory & 3 \\
\hline Chapter 2 & Relation & 6 \\
\hline Chapter 3 & $\begin{array}{c}\text { Function and } \\
\text { infinite set }\end{array}$ & 2 \\
\hline Chapter 4 & Algebra system & 2 \\
\hline Chapter 5 & Group & 4 \\
\hline Chapter 6 & Ring and grid & 4 \\
\hline Chapter 7 & Graph theory & 4 \\
\hline Chapter 8 & Tree & 4 \\
\hline Chapter 9 & $\begin{array}{l}\text { Propositional } \\
\text { logic }\end{array}$ & 8 \\
\hline Chapter 10 & Predicate logic & 8 \\
\hline Chapter 11 & $\begin{array}{c}\text { Discrete } \\
\text { modeling } \\
\text { concepts and } \\
\text { methods }\end{array}$ & 1 \\
\hline Chapter 12 & $\begin{array}{c}\text { Discrete } \\
\text { modeling } \\
\text { application }\end{array}$ & 6 \\
\hline \multicolumn{2}{|c|}{ Class sessions in total } & 52 \\
\hline
\end{tabular}

\section{TEACHING METHODS AND MEANS}

Teaching methods are the key to accomplish tasks of teaching and to improve teaching quality. Therefore selection of appropriate teaching methods can not only improve quality of teaching, but also promote the development of students' abilities and personality. Based on years of teaching experience and the characteristics of discrete mathematics courses, diversified teaching methods can greatly improve the quality of teaching in the teaching process.

\section{A Stimulating learning of students}

Direct and simple coaching methods should not be used in process of teaching. The students should be guided to understand the necessity and importance of discrete mathematics, and their interest in learning discrete mathematics should be stimulated as much as possible. Confucius said "he who knows the truth is not equal to him who loves it, and he who loves it is not equal to him who delights in it”. This is the educational philosophy of interest, and such concept is called "happy education" ${ }^{[4]}$ in modern education. Students with proper interest in learning will be more concentrated on class sessions, and they will also spend time and make efforts to learn. Then students will change from passive learning to active learning, and hence the overall teaching effect will be good. Teachers should design some specific and vivid scenarios to introduce curriculum sessions to stimulate students' interest in learning. For example, we can set a preview questions about condition expression in propositional logic, the question is classic line in film "A Chinese Odyssey": "If God give me another chance, I will...”. Why it will impress Qingxia? It is not important that the student answered correctly or not. The important thing is the students have experienced the process of thinking through this link. In the teaching process, teacher can prompt students thinking by themselves. It can enable students' ability of thinking and master the knowledge points at the same time.

\section{B Heuristic teaching}

The heuristic teaching should be fully applied during classroom teaching. The successful teaching involves participation of students. to focus on teaching the church, and only allow the students to get involved can be called successful teaching. Teachers can first set up a number of questions issues to stimulate students to think independently, guide students to respond freely, and teachers and students therefore together discuss and analyze questions and the solutions. This will not only stimulate students' curiosity and desire for learning knowledge, but also train students' ability to think independently.

For example, the Socrates syllogism (mortals are mortal, Socrates is a man, so Socrates will die) can be used to before explaining predicate logic. If students are asked to prove the correctness of this proposition, the majority of students using the knowledge of propositional logic will first start with propositional symbol and then reasoning. It is clear that this is a correct proposition, but it cannot be justified by using propositional logic. Then students will begin to think, and realize limitations of propositional logic. On this basis, the 
teachers and students together discuss solutions to the problems, and then introduce of the concept of individual words and predicate. The students can then justify the Socrates syllogism through predicate logic learning.

In fact, stimulating students' interest and using the heuristic teaching interlink, and they are not isolated from each other. The ultimate goal is to create active classroom atmosphere no matter what methods are used. Teaching practices show that traditional classroom coaching "chalk and talk" is not desirable, and active and pleasant classroom atmosphere greatly improves the quality of teaching.

\section{Reveal the internal connection of knowledge}

The four major topics of discrete mathematics are relatively independent but mutually connected, so teachers should be able to connect these interactive contents during teaching to reveal the internal connection of knowledge. Set theory is the basis of the whole curriculum, application of the concept of ideological penetration can be seen in each chapter. The relation is subset of Cartesian product, and mapping is a special binary relation. Graph is constituted by edge set and point set, and various sub-graph is subset. Finite set relation can be represented by diagram/graph. Algebraic system is a nonempty set with some calculation, and isomorphism and homomorphism maintain calculation of different mapping. Collection of algebra of set and logic algebra is isomorphic to the Boolean algebra. The relation of the knowledge point shows in the figure 1 . Throughout these knowledge and perspectives in teaching, students can comprehensively understand the knowledge structure and the inherent unity of mathematics.

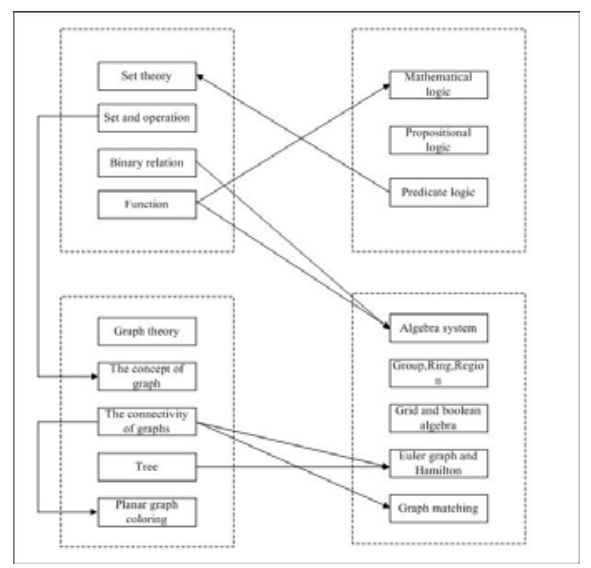

Figure 1. The relation of knowledge point

\section{$D$ Link theory with practice}

Discrete mathematics curriculums are generally pure theory based class sessions. In fact, the ultimate purpose of discrete modeling as a tool is to solve application problems for applied students, so discrete modeling should be an important part of the discrete mathematics curriculum. Fewer and typical examples should be selected to demonstrate discrete modeling. There should not be too many examples. We should also take into account the mathematical support for subsequent courses. All these will strengthen knowledge and practice students' capacity to solve the computer related problems using discrete mathematics. Students will be more aware of importance of learning discrete mathematics.

\section{E Improve teaching methods}

Most universities take the traditional blackboard demonstration to teach discrete mathematics. The amount of information in this way is pretty small, but the whole reasoning and proving process can be presented to students. Multimedia teaching embraces large amount of integrated information and increases interest level of classroom teaching sessions. So these two methods should be combined and used in the process of teaching, according to the course contents. For instance, teachers can use traditional blackboard writing way to help students more clearly understand the process of justification when teaching mathematical logic reasoning. This trains abilities of students in logical thinking and reasoning. A lot of time can be saved if contents such as definition and theorem can be represented by multimedia ways. During teaching process, teachers should be flexible and be able take a variety of teaching methods and means to achieve best teaching results. ${ }^{[5]}$

\section{F Establish web site for teaching}

We also have to consider setting up a website to support teaching. First, teaching resources can be shared through this web site to supplement classroom teaching so that students consolidate their knowledge in a timely manner. Secondly, teachers and students would be much easily to communicate on line and discuss merging questions and their solutions. Finally, if teaching lengthen is not enough, the practical teaching can be finished through web site. Teachers can assign and review homework done by students. This will supplement disadvantages inadequate teaching hours. Diagram 1 below shows function of the proposed web site.

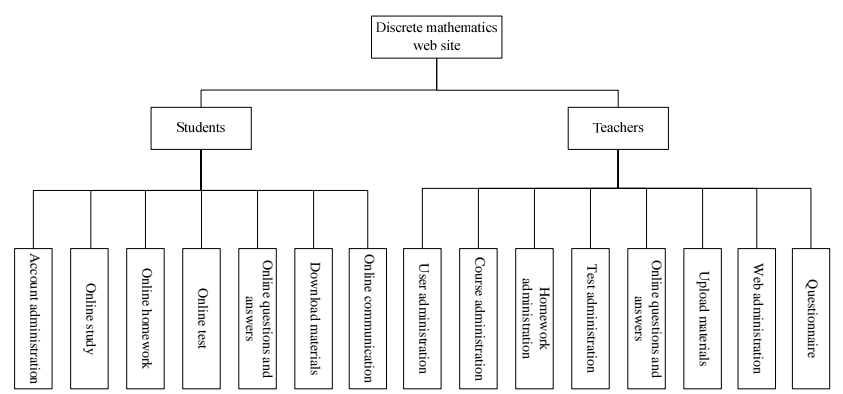

Figure 2. Functional teaching web site for discrete mathematics

\section{CONCLUSION}

As a fundamental computer professional specialized course, discrete mathematics has a very important position in the computer field. Teachers in the process of teaching should increase interest of course to develop students' interest in learning, use flexible and case-based teaching methods, and establish teaching sites. Innovation of teaching reform is to increase the practice of teaching and to select few typical examples of discrete mathematics applications 
in the computer field. This will not only increase interest of students to learn at classroom, but also allow students to fully understand the importance of learning discrete mathematics.

[1] Higher Institution Computer Science and Technology Teaching Guidance Committee of Ministry of Education of the People's Republic of China. Higher School of Computer Science and Technology Professional Development Strategy Report and Professional Standards (for Trial Implementation)[M]. Beijing: Higher Education Press, 2006

[2] Zhihua Gao, Kerong Ben , Xia Liu. Discrete Mathematics Course Content and Discussion of Learning Method [J]. Computer Education, 2011(13):107-109

[3] Jiepan Xu. Foundation Course of Discrete Mathematics [M]. Beijing: China Machine Press, 2009

[4] Lifang Wang, Jinguang Wang. The Application of Pleasant Education Mode for Student Interests in Discrete Mathematics [J].China Electric Power Education,2011(8): 92-93

[5] Haiying Wen, Ruihua Liao, Dakuan Wei. Discrete Mathematics Course Reform and Practice [J]. Computer Education,2010(6): 100103 